\title{
$\sqrt{6}$

\section{"¡Agua zarca y azul!": el abasto de agua potable en la ciudad de Aguascalientes (México), 1856-1896}

\author{
'Light Blue Water': The Supply of Drinking Water in the Mexican City \\ of Aguascalientes, 1856-1896
}

\author{
Universidad Autónoma de Aguascalientes. Aguascalientes, México. jgomez@correo.uaa.mx
}

\begin{abstract}
Resumen - El artículo propone una reconstrucción de los principales problemas relacionados con el abasto de aqua potable en la ciudad de Aguascalientes durante la segunda mitad del siglo XIX. Se documenta la multiplicación de fuentes públicas, así como los problemas derivados del uso de la acequia que iba del manantial a la ciudad, la cual, a su paso, alimentaba unos baños públicos. Se señalan también los primeros intentos que hubo para entregar agua a domicilio por medio de cañería y el papel que desempeñaron los aguadores, tanto para abastecer las necesidades de agua potable como para la empleada en otras tareas domésticas. Al final se proponen algunas reflexiones sobre la crisis del sistema de abasto en línea a fines del siglo XIX y la medida en que muchos problemas propios del viejo orden porfiriano siguieron presentándose durante la primera mitad del siglo XX. El artículo utiliza en su mayor parte fuentes originales, sin descuidar el diálogo con diversos autores que se han ocupado de estos temas en otros lugares.

Abstract - The article proposes a reconstruction of the main problems related to the drinking water supply in the city of Aguascalientes during the second half of the nineteenth century. It documents the multiplication of public water fountains, as well as the problems arising from the use of a canal supplying water from a spring to the city, which fed bathhouses along the way. The essay al so looks at the first attempts to deliver water to homes through pipes and water carriers, both of which were used to meet the needs for drinking water and for other household needs. Towards the end of the paper we propose some reflections on the crisis of the late 19th-century water supply system, and the extent to which many water-related problems associated with the regime of Porfirio Díaz appeared during the first half of the twentieth century. The article draws mostly on original sources, without neglecting the dialogue with various authors who have dealt with these issues elsewhere.
\end{abstract}

Palabras clave: México, historia urbana, servicios públicos, gestión del agua, aguadores
Keywords: Mexico, urban history, public services, water management, water suppliers

Información Artículo: Recibido: 13 septiembre 2016

Revisado: 11 febrero 2017
Aceptado: 23 abril 2017

(c) Universidad de J aén / Seminario Permanente Agua, Territorio y Medio Ambiente (CSIC) 


\section{INTRODUCCIÓN}

Con una extensión de $5.600 \mathrm{~km}^{2}$, Aguascalientes es uno de los estados más pequeños de la república mexicana. Su capital se fundó con categoría de villa en 1575 y a principios del siglo XVII se convirtió en cabecera de una de las alcaldías mayores de la Nueva Galicia. En 1786, con la creación del régimen de intendencias, se transformó en subdelegación de la intendencia de Guadalajara, pero en 1804 el Consejo de Indias determinó agregarla a la de Zacatecas. En 1825, al proclamarse la primera constitución política de este estado, se convirtió en uno de sus partidos y a su capital se le concedió el título de ciudad. En 1835, en el contexto de la crisis de la primera república federal, Aguascalientes lograría emanciparse, siendo primero territorio de la federación, luego departamento de la república central y finalmente estado libre y soberano de la federación. Durante el porfiriato, gracias al trazo de la línea troncal del Ferrocarril Central Mexicano, Aguascalientes experimentó un notable crecimiento industrial y duplicó su población (22.500 habitantes en 1861, 31.000 en $1895,35.000$ en 1900 y 45.000 en 1910, cifra esta última que la convirtió en la séptima ciudad más poblada del país) ${ }^{1}$.

El abasto de agua mejoró de forma notable en la ciudad de Aguascalientes a fines del siglo XIX, con algunas décadas de retraso con respecto a lo que puede observarse en Europa occidental o la costa este de los Estados Unidos. A lo largo del siglo XIX, conforme "se vislumbró la posibilidad de llevar agua directamente a las casas", se empezaron a hacer realidad "las ideas de los higienistas británicos". Hacia 1850, en Londres, "casi todas las casas poseían una cisterna que se llenaba a horas convenidas". En París se construyeron entre 1862 y 1874 dos gigantescos acueductos que garantizaban el abasto, al tiempo que se persuadía a los parisinos de las ventajas del agua limpia pero traída de lejos sobre la del río Sena, a la que estaban secularmente acostumbrados. Los progresos fueron igualmente asombrosos en Estados Unidos, pues Filadelfia, la primera capital, contaba con una red de abasto desde 1801. Pese a estos avances y al hecho de que "la tecnología de los equipamientos hidráulicos evolucionó muy rápidamente", hay que reconocer que "la revolución del suministro domiciliario de agua corriente" se produjo con lentitud, entre otras razones porque "los usuarios se negaban a pagar por el agua" y no toleraban la idea de abonarse obligatoriamente. Por ello, este cambio

1 Epstein, 1861. Estadísticas sociales del Porfiriato, 9. fundamental en la vida de las ciudades tomó como norma general varias décadas "y en algunos lugares casi un siglo" 2 .

El objetivo de este artículo es caracterizar los principales problemas que enfrentó la ciudad de Aguascalientes en materia de abasto de agua durante la segunda mitad del siglo XIX, siguiendo las ideas de Goubert y Matés sobre la institucionalización de la higiene y la "conquista del agua" 3 . Al igual que en otras muchas ciudades mexicanas, como Querétaro, Toluca, Puebla, San Luis Potosí, León, Zacatecas y la propia capital de la república ${ }^{4}$, en Aguascalientes el crecimiento de la población y la emergencia de
Mapa 1. Localización regional del estado de Aguascalientes, México

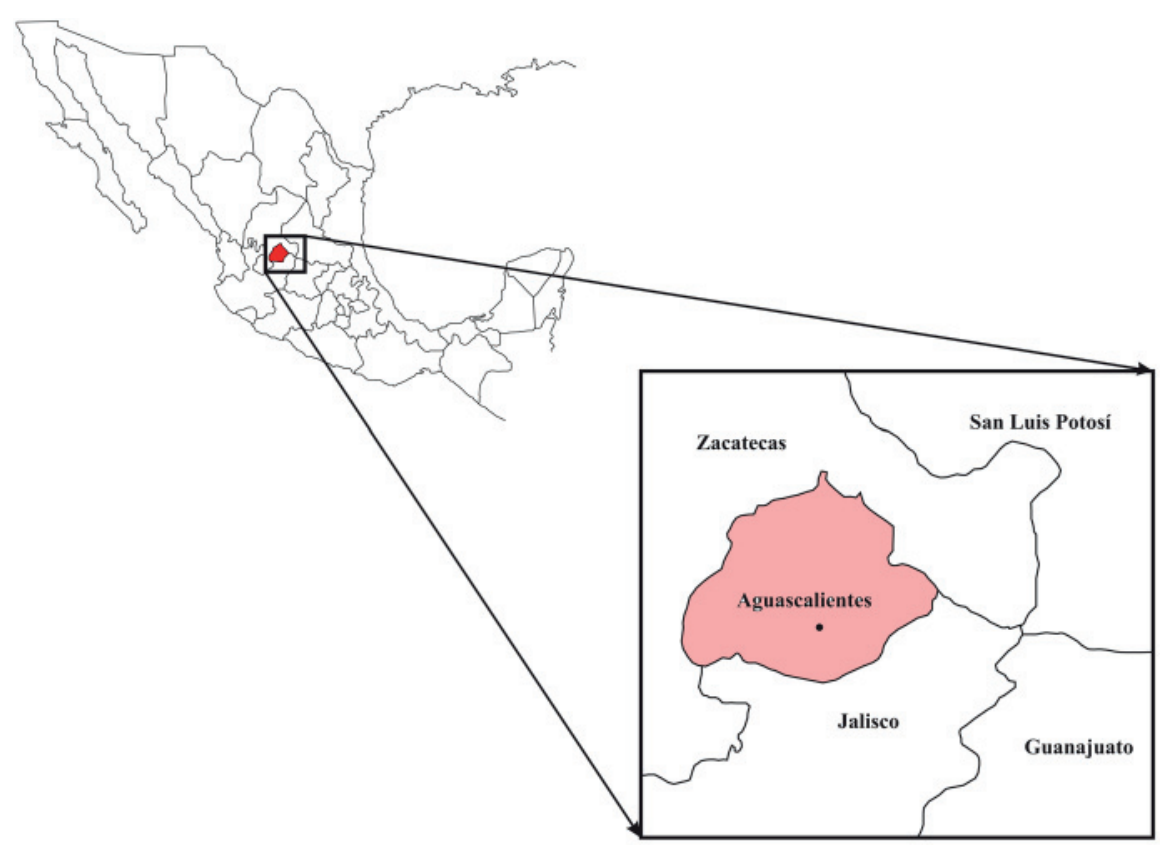

Fuente: INEGI, Mapa Geoestadístico Nacional, 2005. Dibujo de Marlene Barba Rodríguez.

una nueva cultura de la higiene determinaron la multiplicación de las fuentes públicas, circunstancia que -a su vez-implicó una presión adicional sobre el manantial del Ojocaliente, que había dado de beber a los habitantes del lugar, regando de paso sus numerosas huertas desde el siglo XVI. El viejo sistema de acequias se mostró crecientemente incapaz de atender los requerimientos de la población, al tiempo que se reparaba en la dudosa calidad del agua que se bebía y se usaba en las cocinas.

En la década de 1870 empezó a entregarse agua a domicilio por medio de cañería y los aguadores se multiplicaron; entre estos había algunos que vendían agua supuestamente potable, llevada desde manantiales cercanos, y otros que se abastecían en las fuentes públicas y entregaban agua empleada luego en diversas tareas domésticas. El título de nuestro artículo recoge el redundante pregón que anunciaba la venta de agua procedente del ma-

2 Matés, 2013, 24.

3 Goubert, 1989. Matés, 1999 y 2013.

4 Alfaro, 2011 y 2013. Suárez, 1998. Castañeda, 1998 y 2007. Birrichaga, 1998 y 2007. Camacho Pichardo, 2007. Camacho Altamirano, 2007. Iracheta, 2007. Loreto, 2010. Toxqui, 2013. 
nantial de Los Negritos. El sistema de abasto "en línea" entró en crisis a fines del siglo XIX y sería objeto de una intervención radical, aunque muchos problemas se mantuvieron vigentes hasta bien entrado el siglo XX, como luego documentaremos.

En su parte medular, nuestro trabajo está basado en documentación de archivo y constituye una aportación a los estudios sobre la historia ambiental, en particular sobre el aprovisionamiento y los usos del agua. Su autor comparte la idea de que los estudios de carácter local son importantes porque suministran "información detallada", enriquecen la visión de conjunto y hacen posibles los estudios comparados. Nuestra hipótesis es que a lo largo de la segunda mitad del siglo XIX hubo una tensión no resuelta entre la creciente demanda de agua de parte de los habitantes de la ciudad y la capacidad del Cabildo para atender esos requerimientos, derivada - por un lado- de su falta de recursos económicos y -por el otro- de los términos en que se consumó la desamortización de los baños de Los Arquitos. En octubre de 1856, en ejecución de la Ilamada Ley Lerdo ${ }^{6}$, el Cabildo de la ciudad de Aguascalientes le vendió a J esús Carreón esos baños de Los Arquitos, el acueducto que iba del manantial del Ojocaliente a los baños y el agua que corría por él, reservándose tan solo una naranja ${ }^{7}$, de la que dispondría "como y cuando lo tenga por conveniente para las fuentes públicas" ${ }^{8}$. Ello colocó al Cabildo en una situación de impotencia y agravó el desabasto que padecía la ciudad. Los problemas no fueron resueltos de manera satisfactoria hasta 1896, cuando el gobierno del estado (no el Cabildo) emprendió la construcción de un moderno sistema de abasto en red, aunque ese no es el tema de nuestro artículo, centrado en el análisis del antiguo sistema de abasto en línea y el papel de los aguadores.

\section{Fuentes Públicas}

Los manantiales del 0jocaliente se ubican a 2.880 metros al este de la plaza de la ciudad, un kilómetro más allá de donde en 1883 se construyó la estación del Ferrocarril Central Mexicano, y originalmente formaban un "arroyuelo perpetuo" que proveía "agua muy dulce y sana" al vecindario ${ }^{9}$. El agua bajaba por gravedad, aprovechando la pendiente natural del terreno, a diferencia de lo que sucedía en Guadalajara, ciudad fundada en un punto más alto respecto de las fuentes que la abastecían, lo que exigió costosas obras para elevar las aguas y llevarlas hasta los puntos de consumo ${ }^{10}$. El crecimiento de la villa hizo necesaria la construcción de una acequia, que alteró el curso del arroyo, pero se trataba de una zanja sin revestimiento a lo largo de la cual se

5 Matés, 2013, 24.

6 Decreto del gobierno "sobre desamortización de fincas rústicas y urbanas que administren como propietarios las corporaciones civiles o eclesiásticas de la República", Dublán y Lozano, 1876-1912, Disposición N 4715, 25 de junio de 1856, tomo VIII.

7 La naranja es una medida antigua que en México equivalía a 64,8 litros por minuto, o sea, 3.888 litros por hora y $93,3 \mathrm{~m}^{3}$ al día.

8 Archivo Histórico del Estado de Aguascalientes, Fondo Protocolos Notariales (en adelante, AHEA-FPN), caja 66, expediente 4, fojas 238v-245v. Dávila, $1985,77$.

9 De la Mota, 1966, 58.

10 Torres, 2013, 318, 322-323. formaban verdaderos pantanos. En abril de 1896, en el contexto de la reforma del sistema de abasto de agua de la ciudad, se determinó con procedimientos técnicos creíbles que el manantial descargaba 1.037 litros de agua por minuto $\left(62,2 \mathrm{~m}^{3}\right.$ por hora, $1.493 \mathrm{~m}^{3}$ al día) ${ }^{11}$.

En términos de los requerimientos actuales de agua potable, la reserva que hizo el Cabildo en 1856 de una naranja de agua al día para abastecer las fuentes públicas resulta ridícula, pero hay que recordar que la "conquista" del agua es muy reciente ${ }^{12}$. En 1891, más de treinta años después de vendidos los baños, un médico de la localidad reconocía que el agua era uno "de los elementos indispensables para la vida" y que "ninguna población puede desarrollarse convenientemente si no tienen en cantidad suficiente este elemento para todos los usos ordinarios de la vida", pero al mismo tiempo advertía que no era posible "fijar la cantidad de agua que pueda consumirse por cabeza", pues ello dependía de múltiples variables, como "el grado de cultura", las costumbres y "necesidades" específicas, que cambiaban "de una clase social a otra", e incluso entre las familias ${ }^{13}$.

$\mathrm{Si}$ consideramos que el manantial descargaba $1.493 \mathrm{~m}^{3}$ diarios y que la ciudad tenía 31.000 habitantes en 1895, puede estimarse que se disponían de 48 litros de agua por habitante, aunque este es un prorrateo simple, que ignora las considerables mermas que había en el trayecto desde el manantial hasta las fuentes públicas, el hecho de que la mayor parte del agua se dedicaba a regar las numerosas huertas de la ciudad (había 459 en 1883) y la previsión contenida en el contrato de venta de los baños de Los Arquitos, según la cual el Cabildo no disponía de toda el agua del manantial, sino solo de una naranja (93,3 $\mathrm{m}^{3}$ al día). Como punto de comparación podemos mencionar que en España, a mediados del siglo XIX, se calculaba que eran necesarios 150 litros diarios de agua por habitante, aunque Sevilla, la tercera ciudad más poblada de la Península, contaba apenas con treinta o cuarenta litros por habitante ${ }^{14}$. El cabildo de Zacatecas, por su parte, calculó en 1832 que era necesario contar con cuarenta litros diarios de agua por habitante $e^{15}$.

El agua del manantial del Ojocaliente pertenecía a la villa y a sus horticultores, lo que se formalizó en 1644 mediante un título de composición que se ajustó con el oidor Cristóbal de Torres. Aunque siempre hubo tensiones ocasionadas por la falta de agua en las acequias y los abusos de los cultivadores, nunca se pusieron en duda los derechos preferentes del "común" sobre los veneros ${ }^{16}$. Ello se inscribe en el marco de la tradición hispánica medieval que daba a las ciudades derechos sobre las aguas que brotaban de los manantiales cercanos y eran conducidas hasta las fuentes públicas construidas "al interior del recinto amurallado". Barcelona disponía de las aguas de Collserola, Valladolid de las de Argales, y Sevilla de la Fuente del Arzobispo, cuyas aguas eran llevadas a la Alameda de Hércules por un acueducto construido en

11 Archivo General Municipal de Aguascalientes, Fondo Histórico (en adelante, AGMA-FH), caja 225, expediente 24.

12 Goubert, 1989, 21. Matés, 1999, 25.

13 Díaz de León, 1892, 199.

14 Matés, 1999, 107.

15 Alfaro, 2013, 95.

16 Gómez, 2014a. 
1574. En Madrid había un considerable número de fuentes, incluidas las "santas", cuyas aguas supuestamente tenían capacidades curativas. La población tomaba libremente agua en todas estas fuentes, sin ningún costo, salvo "el esfuerzo de acarrearla" ${ }^{17}$.

En 1860, el "año de las ideas", del triunfo liberal y de la Reforma ${ }^{18}$, solo cuatro años después de vendidos los baños de LoS Arquitos, se llevaron a cabo algunas mejoras del sistema de abasto de agua en la ciudad. Se trataba de obras sencillas, pero como habían transcurrido varias décadas sin que nada se hiciera, la prensa pudo conceptuarlas como grandiosas, pruebas palpables de que en todos los campos "el partido liberal aventaja en mucho al conservador" ${ }^{19}$. Sin embargo, el proyecto no fue del agrado de los horticultores, que en el contexto de una disputa anterior habían expresado su convicción de que eran "dueños y poseedores del agua del 0jocaliente", que estaba dedicada precisamente "a los regadíos de las huertas"; informados de que el Cabildo "piensa darle otra dedicación a el agua expresada, aplicándola a fuentes 0 pilas de las plazas públicas", denunciaron que con ello "va a resultar perjudicado en sumo grado el ramo de la horticultura", actividad en la cual "tienen fincada su subsistencia" 20. Vale la pena citar este reclamo porque remite a la disputa por la propiedad y el uso del agua que maduró durante todo el siglo XIX entre los horticultores y el Cabildo, que dejó de concebirse como simple administrador del agua para erigirse en su propietario primordial, facultado para darle nuevos usos, que desde su perspectiva tenían que conciliarse con el tradicional riego de huertas.

En agosto de ese mismo año, ya restablecido a nivel local el orden constitucional, el Cabildo decidió construir "una magnífica fuente" en la calle del Obrador, abastecida con agua del manantial del Cedazo, que hasta esa época llegaba solo a la plazuela de Triana ${ }^{21}$. Se formó una "comisión" compuesta de ciudadanos "constantes y decididos partidarios de las mejoras materiales", lo que según eso garantizaba "que la obra no quedará en proyecto, como la mayor parte de las que emprendemos los mexicanos 'mientras no se acabe de purificar nuestra sangre de la de nuestros conquistadores' "22. Uno de esos personajes era precisamente J esús Carreón, el beneficiario de la desamortización de los baños de Los Arquitos. La comisión decidió "erigir tres fuentes en lugar de una, la primera en la hermosa plazuela de Triana, la segunda en la calle de la Cárcel y la tercera en la calle del Obrador". La de Triana empezó a funcionar el 12 de noviembre y fue pagada por el presbítero Agustín Gómez, cura párroco del Encino. Poco después empezó a funcionar la de la calle del Obrador, e incluso se comentó que pronto se construirían otras en la calle de La Merced, en la plazuela de San J uan de Dios, en el jardín de San Marcos "y en muchas casas particulares".

17 Matés, 1999, 111-113, 120, 132.

18 González, 1881, 286-287.

19 El Porvenir, Aguascalientes, 26 de diciembre de 1860.

20 AHEA-FPN, Not. Pablo González Hermosillo, 1854, s. n., 123-126.

21 Gómez, 2014.

22 El Porvenir, 12 de agosto de 1860. Las cursivas son mías y remiten a esa concepción tan típicamente liberal de la herencia española como lastre; "es innegable que el sentimiento antiespañol era singularmente fuerte en México", escribe Hale $(1972,102)$, quien añade que la mecha del anti-españolismo se encendió en 1827, con motivo de la "conspiración" del padre J oaquín Arenas.
La inestabilidad de la época y la falta de recursos en las arcas públicas impidieron que algunas de esas mejoras se hicieran; la fuente de la calle de la Cárcel no fue construida, pero a fines de marzo de 1861 se informaba que la de la calle de la Merced "se concluirá pronto". La de la calle del Obrador, que se bautizó oficialmente como "fuente de la Reforma", fue criticada por sus dimensiones, excesivas al parecer para el lugar preciso que ocupaba, aunque se reconocía su "inmensa utilidad". Solo unos meses después, en la propia prensa liberal se documentaba que la elevada presión con la que llegaba el agua a las fuentes de Triana y la Reforma había provocado la ruptura de las cañerías, con la consecuente pérdida "del trabajo, el tiempo y el dinero invertidos". El redactor decía que la culpa la tenían "la imprecaución (sic) y falta de conocimientos" de Diego P. Ortigosa, vocal de la junta de fuentes. Aparentemente los problemas no se corrigieron, pues en enero de 1862 se lamentaba que el ayuntamiento hubiera invertido "más de seis mil pesos en fuentes" sin que se hubieran obtenido los resultados que se esperaban ${ }^{23}$. En 1861 la ciudad contaba con cinco fuentes públicas.

Con el paso del tiempo, conforme creció la urbe y lo permitieron los escasos fondos del Cabildo, fueron habilitándose nuevas fuentes. En 1877 había once surtidas por el manantial del Ojocaliente, una de ellas en la cárcel de hombres, pero había muchas quejas sobre su funcionamiento, pues para empezar solo tenía agua cada tercer día24. Si añadimos las tres fuentes del barrio del Encino, abastecidas por el acueducto del Cedazo, podemos suponer que la ciudad contaba con catorce fuentes en total. En 1880 se construyeron cuatro fuentes en la plaza principal de la ciudad, pero su funcionamiento fue muy deficiente y se pidió la asesoría del ingeniero Miguel Velázquez de León, a quien se suponía versado en esta clase de asuntos.

En su dictamen, Velázquez de León dijo que el problema de las nuevas fuentes era que estaban a "diversas alturas" con respecto a la alcantarilla que las abastecía, lo cual implicaba que se tenía que repartir de manera uniforme el "gasto" o presión del líquido. Como no se había tenido en cuenta este sencillo principio, las cañerías se reventaban y de nada servía reponerlas, pues a los pocos días volvían a colapsarse. Lo que debía hacerse era "dividir la corriente de agua que conduce la cañería principal en cuatro cañerías paralelas", de diferentes tamaños y con "codos de desiguales amplitudes". En resumen, recomendó que la caja repartidora se rehiciera, que las cañerías de barro de las fuentes se cambiasen por otras de plomo, supuestamente más resistentes, y que la tubería de cada una de las cuatro fuentes contara con una llave de bronce que regulara su gasto $0^{25}$. La plaza contó a partir de entonces con cinco fuentes y se convirtió en el principal punto de reparto de agua para usos domésticos en toda la ciudad.

A estos problemas se añadía la carencia de recursos del Cabildo. En los albores del porfiriato existía ya un consenso muy

23 El Porvenir, 2 de octubre de 1860, 15 de noviembre de 1860, 26 de diciembre de 1860, 28 de marzo de 1861, 5 de mayo de 1861 y 12 de enero de 1862.

24 AGMA-FH, caja 104, expediente 5.

25 "Consulta hecha al Sr. Velázquez de León sobre las modificaciones o reformas que necesiten las cuatro fuentes nuevas que se construyeron en la plaza principal", 21 de junio de 1880, AGMA-FH, caja 105, expediente 17. 
amplio en el sentido de que debía ampliarse la oferta de agua y construirse nuevas fuentes; en sí, las obras no eran muy costosas, pero la mayor parte de las veces el ayuntamiento de la capital del estado no tenía el dinero necesario. En 1887, por ejemplo, se acordó la construcción de cuatro nuevas fuentes en el jardín de San Marcos, para lo cual el Cabildo tuvo que "suplicarle" al Congreso que autorizara una inversión de trescientos pesos ${ }^{26}$. Esta inopia le da su verdadero sentido a gestos que de otra manera parecerían apenas simbólicos, como el que tuvo el escribano Alberto M. Dávalos, quien en agosto de 1890 hizo entrega muy solemne de "dos juegos de llaves de agua para las fuentes públicas de esta ciudad", obsequio de su difunto padre, don Timoteo Dávalos ${ }^{27}$.

Felipe Ruiz de Chávez, un presidente municipal particularmente emprendedor, podía informar en septiembre de 1890 que las 21 fuentes públicas que había en la ciudad estaban activas y que para asegurar su buen servicio "se han hecho fuertes gastos en reparaciones de alcantarillas, repartimientos y llaves, porque son muy antiguas las cañerías y están en su mayor parte azolvadas y reventadas". Además, había varias fuentes "privadas". Por ejemplo, la que construyó Reyes M. Durón, dueño de la fábrica de hilados La Purísima, que daba servicio al público ${ }^{28}$. Querétaro, una ciudad más grande y poblada que Aguascalientes, tenía 38 fuentes públicas, incluidas ocho que estaban "fuera de la ciudad", pero algunas no funcionaban por razón de su deterioro y otras solo contaban con agua "en días festivos", lo cual provocaba que las fuentes que estaban más abajo dispusieran de un caudal menor ${ }^{29}$. En 1880 Guadalajara tenía ochenta "pilas 0 fuentes", completamente incapaces de abastecer una ciudad de 107.000 habitantes ${ }^{30}$.

\section{La "aCEQUia profanada"}

En la prensa eran frecuentes las quejas sobre la falta de agua en las fuentes públicas. Aunque deben leerse con cuidado, por su carácter impreciso y muchas veces alarmista, citemos a título de ejemplo una nota de mayo de 1896, en la que se dice que las huertas perecían, los vecinos renegaban porque "las fuentes no tienen agua si no son dos horas por la noche" y los aguadores habían duplicado el precio de sus cántaros, todo ello mientras el ayuntamiento regaba "Ias solitarias calles del barrio del Tanque", donde se iba a celebrar la fiesta de la Santa Cruz, que no era

26 "Autorización que pidió el Ayuntamiento al H. Congreso del Estado para gastar \$300 en la construcción de cuatro fuentes en el jardín de San Marcos, 24 de enero de 1887", AGMA-FH, caja 161, expediente 24.

27 "Comunicación del Lic. Alberto M. Dávalos, remitiendo para las fuentes públicas de esta ciudad dos juegos diferentes de agua como obsequio al Municipio, 21 de agosto de 1890", AGMA-FH, caja 174, expediente 25.

28 "Informe rendido por el presidente del Ayuntamiento Felipe Ruiz de Chávez", El Republicano, Aguascalientes, 28 de septiembre de 1890; Martínez, 2009, 152. En febrero de 1887 Antonio Morfín Vargas tenía en construcción su fábrica de tabacos labrados La Regeneradora, en la calle de Victoria, y solicitó permiso al Cabildo para construir una fuente "en el centro del patio" de la casa que ocupaba su taller, para lo cual sería necesario hacer una canalización desde la plaza principal, a una cuadra de distancia. El expediente no lo dice, pero del informe del presidente municipal puede inferirse que no se autorizó la construcción de esta fuente. AGMA-FH, caja 161, expediente 7.

29 Suárez, 1998, 33-34.

30 Torres, 2013, 337-345.
Tabla 1. Fuentes públicas y privadas en la ciudad de Aguascalientes en 1891

\begin{tabular}{|l|c|l|}
\hline \multicolumn{1}{|c|}{ Públicas } & Número & \multicolumn{1}{|c|}{ Abasto } \\
\hline Plaza principal & 5 & Ojocaliente \\
J ardín de San Diego & 4 & Ojocaliente \\
Mercado Terán & 1 & Ojocaliente \\
Jardín de Zaragoza & 1 & Ojocaliente \\
J ardín de San J uan de Dios & 1 & Ojocaliente \\
J ardín de Guadalupe & 1 & Ojocaliente \\
Jardín de la Merced & 1 & Ojocaliente \\
Jardín de San Marcos & 5 & Ojocaliente \\
Plaza del Encino & 1 & Cedazo \\
Calle del Obrador & 1 & Cedazo \\
Hotel de los Chávez & 1 & Cedazo \\
Subtotal & 22 & \\
\hline Privadas & & \\
Hospital Civil & 1 & Ojocaliente \\
Cárcel de hombres & 1 & Ojocaliente \\
Teatro Morelos & 1 & Ojocaliente \\
"Mercedada a particular" & 1 & Cedazo \\
Subtotal & 4 & \\
Total & 26 & \\
\hline
\end{tabular}

Fuente: Díaz de León, 1892, 200, 204; "Informe rendido por el presidente del Ayuntamiento Felipe Ruiz de Chávez", El Republicano, Aguascalientes, 28 de septiembre de 1890.

más que "un paseo de borrachos". Y añadía que "ni en San Luis ni en Zacatecas sucede lo que aquí, donde falta el agua en lo absoluto" ${ }^{31}$. Por esas mismas fechas, en otro periódico, se decía que "los vecinos del barrio de Guadalupe están careciendo desde hace tiempo del precioso líquido", pues la única fuente con que contaban no proveía el suficiente ${ }^{32}$.

En teoría, el contrato de desamortización de los baños de LoS Arquitos tenía la ventaja de que su dueño iba a cargar con la responsabilidad de conservar la acequia "siempre en buen estado", pero también implicó que el abasto de agua de la ciudad quedó a merced de un particular, que podía o no aplicarse en la conservación de esa obra. La experiencia demostró que los dueños de los baños nunca tuvieron ningún sentido de responsabilidad con respecto al abasto público de agua.

Los conflictos que se presentaron a partir de 1856 remiten al pésimo estado del acueducto, las dificultades técnicas y financieras para hacer las reparaciones necesarias, la negligencia de los dueños de los baños y la incapacidad del Cabildo para lograr que prevalecieran los intereses de la ciudad. Cuando los vecinos se quejaban porque faltaba agua en las fuentes públicas, el jefe político del partido o el regidor encargado del ramo de regadíos inspeccionaban el acueducto y encontraban grandes fugas, pero los dueños de los baños siempre tenían buenas razones para no hacer las reparaciones o para hacerlas solo en forma parcial. En febrero de 1871, por ejemplo, las autoridades reportaron una fuga en la cañería, lo que tenía como consecuencia que escasea-

31 "Falta de agua en fuentes públicas", El Fandango, Aguascalientes, 10 de mayo de 1896.

32 "Falta de agua en la fuente de Guadalupe", El Correo del Centro, Aguascalientes, 3 de mayo de 1896. 
Mapa 2. Fuentes públicas y privadas en la ciudad de Aguascalientes, 1891

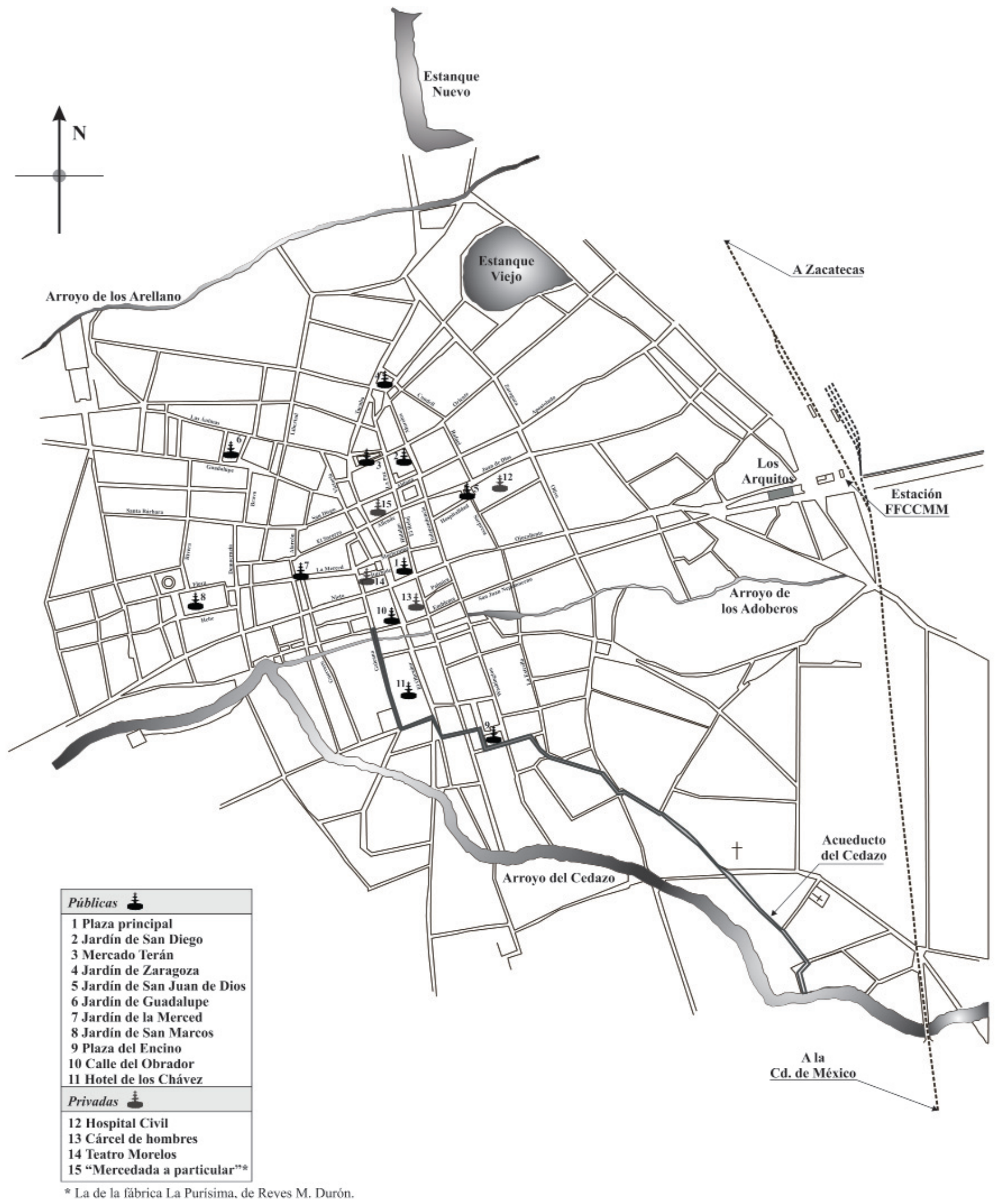

Fuente: reconstrucción propia sobre Ruiz de Chávez, 1890. Díaz, 1892. Medina, 1900. Dibujo: Barba Rodríguez, Marlene. 
ra el agua en las fuentes públicas de la ciudad, pero la dueña de los baños, no encontró "el lugar en que pueda haber la rotura"; por el contrario, aprovechó la oportunidad para ofrecer su propio diagnóstico del problema, que consistía en que al lado y en determinados pasajes abajo o encima de la cañería que llevaba el agua a los baños y a las fuentes de la ciudad, había una "acequia de dominio público", en la que mucha gente acostumbraba bañarse o lavar su ropa ${ }^{33}$.

Esta costumbre, por cierto, fue acremente censurada por diversos personajes. Eduardo J. Correa se refirió a la "acequia profanada", "convertida en lavadero", un lugar en el que se veían "repugnantes escenas que nada más pueden halagar lujurias incipientes 0 tardías" 34 . Estas observaciones fueron puestas por Correa en boca de su padre, el abogado Salvador E. Correa, protagonista del "viaje a Termápolis", y por lo mismo es muy interesante advertir que en un periódico católico que publicaba este último se denunciaban en 1891 "Ios desórdenes que se cometen en la acequia del 0jocaliente, al bañarse juntos hombres y mujeres" ${ }^{35}$. Interesante es, además, advertir que ese mismo año el higienista Díaz de León apuntaba que esa acequia "sirve de baño público a la mayoría de la gente pobre de la ciudad", y también de lavadero, aunque no solo para los pobres, "sino a toda la ciudad, pues los lavaderos que se construyeron en los baños de Los Arquitos no son frecuentados por las lavanderas de profesión sino con pocas excepciones", seguramente porque su uso tenía un costo y lavar ropa en la acequia pública era gratuito. Añadía que la costumbre de la gente de bañarse en la acequia tenía implicaciones para la "moral pública", "pues dicha acequia pasa cerca de la estación del Ferrocarril Central y los bañistas están a la expectación pública, lo que no es de buen efecto, particularmente a los extranjeros". Aunque la gente estaba acostumbrada a ese espectáculo, incluso el público instruido, del que Díaz de León era el mejor vocero, no dejaba de sentir "alguna repulsión siempre que hacemos alguna excursión por la alameda del Oj ocaliente". Era necesario poner un remedio a esa situación, no solo para que los touristas no siguieran censurando "la falta de acatamiento en nuestras costumbres a la moralidad pública", sino sobre todo porque semejante hábito "ahoga el pudor y facilita el incentivo de las pasiones", lo cual sin duda contribuía "en gran parte para elevar la cifra de los delitos de incontinencia que se registran en los tribunales" 36 .

\section{Agua A domicilio}

En la segunda mitad del siglo XIX, como un fiel reflejo de la difusión de nuevos hábitos de salud e higiene, aparecieron las peticiones de particulares que querían contar con agua potable en sus casas. Los argumentos expuestos por los peticionarios y la respuesta del Cabildo, concediendo algunas y negando otras, remiten a un fenómeno que con ritmos diferentes se vivió en la

33 "J osefa G. de Carreón, dueña de los baños de Los Arquitos, dice que falta agua porque está rota la cañería y por el aumento del número de fuentes públicas, 18 de febrero de 1871", AGMA-FH, caja 71, expediente 2.

34 Correa, 1937, 220-221.

35 El Soldado de la Fe, Aguascalientes, 29 de abril de 1891.

36 Díaz de León, 1892, 200-201, 220-221.
Imagen 1. La acequia del Ojocaliente, "una de las más concurridas por las clases populares" hasta bien entrado el siglo XX

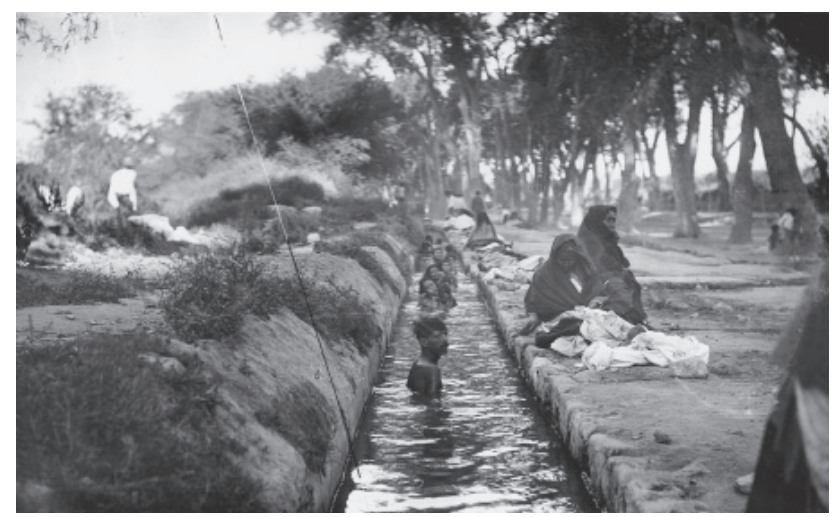

Fuente: Fotografía de William J ackson, Fototeca del Archivo Histórico del Estado de Aguascalientes (en adelante, AHEA).

ciudad de México y en muchas capitales de provincia: la emergencia de "una verdadera cultura de la higiene", uno de cuyos pilares fundamentales era el aseo corporal, el cual, a su vez, dependía directamente de la posibilidad de "contar con el suministro de agua potable" 37 . Poco a poco empezaron a crecer las tomas de agua domiciliarias; en Toluca, por ejemplo, había 70 en 1864, 116 en 1881 y 168 en 188938. Para que las casas contaran con agua potable no había más que dos opciones: que la casa contara con un reservorio propio (aljibe o pozo) o que el abasto proviniera de las cañerías públicas. En diversos puntos de la ciudad de Aguascalientes se construyeron exitosamente pozos, encontrándose aguas "someras" a menos de diez metros de profundidad ${ }^{39}$. En el boliche Hidalgo, ubicado en la calle de Los Gallos, había uno que tenía solo cinco metros, aunque el del mesón del Burro tenía veintiocho. En la huerta de la fábrica de hilados y tejidos de la Purísima, el antiguo Obraje, en el barrio de Triana, había "una noria de gran capacidad", perforada a solo nueve metros, que proveía "agua potable de buena calidad" con la que se enfriaba la caldera del establecimiento.

Por otra parte, unas pocas casas contaban con aljibes en los que se recogía el agua de lluvia, que podía beberse "en casi todo el año". Según Díaz de León solo había siete aljibes en toda la ciudad; uno de ellos, el del antiguo convento de San Diego, reconvertido en Instituto de Ciencias, estaba "obstruido" y las autoridades del plantel no parecían interesadas en limpiarlo y aprovechar sus aguas ${ }^{40}$. Arturo Pani recuerda que, en su casa, ubicada a unos pocos metros del templo de San Diego, se tenía el cuidado de barrer las azoteas y limpiar el aljibe una vez al año,

37 Agostini, 2005, 564, 571-572.

38 Castañeda, 1998, 153-154.

39 Viene a colación la distinción entre agua freática, somera o de pozo, y agua artesiana: "La primera es aquella que se halla a mayor o menor profundidad, pero por encima de la primera capa impermeable del subsuelo. La segunda, en cambio, es aquella más profunda que se halla cubierta o encerrada entre capas impermeables salvo en su lugar de origen y que por ello genera una presión diferente a la del acuífero libre, lo que la hace subir a la superficie". (Aboites, 1998, 168).

40 Díaz de León, 1892, 205-206. 
antes de que iniciaran las Iluvias, "para almacenar en él desde el primer aguacero" 41

Seguramente por razones de comodidad y menor costo, la opción que emergió con más fuerza a partir de 1870 fue la de solicitar mercedes de agua al Cabildo. La primera solicitud que tenemos documentada data de marzo de 1871 y fue hecha por la señora Martha Aldana de Camarena, que vivía en la calle de Tacuba, a un costado de la iglesia parroquial. Argumentando su deseo de tener "el agua necesaria para el aseo y limpieza" de su casa "y la comodidad de mi familia", solicitó que se le permitiera "tomar de los caños que surten la fuente de la plaza principal una paja de agua" [648 I/ día], que conduciría hasta su destino a través de una "cañería construida y mantenida en buen estado por mi cuenta". La comisión encargada de estudiar el asunto dictaminó favorablemente, aunque tomando en cuenta que "en el presente negocio se trata de una enajenación perpetua" y con el propósito de "garantizar debidamente los intereses de la Corporación", recomendó que se impusiera a la interesada el pago de una cuota ${ }^{42}$.

Hasta donde sabemos este fue el primer domicilio particular que contó con una merced de agua, un servicio que con el paso del tiempo no haría más que generalizarse. Conviene observar, sin embargo, que el arranque fue lento e incluso torpe, como lo acredita el tratamiento que se dio a la solicitud que presentó en junio de 1877 la señora Dolores Herrera de Felguérez, vecina de una finca ubicada en la esquina de la plaza principal, "frente a la casa del Estado". Argumentando que su casa carecía de pozo y que sería necesario "erogar algún gasto en hacerlo", juzgó preferible "construir una pequeña fuente en el patio" y abastecerla con agua procedente de la cañería pública, pagando "una retribución equitativa y moderada". En aquella ocasión las comisiones encargadas de estudiar el asunto dijeron que había "muchas y poderosas razones" para negar lo solicitado, pero se contentaron con recordar que el manantial del Ojocaliente "surte diez fuentes públicas y una de la cárcel de hombres", siendo frecuente que "se quitara a unas para darla a otras, no pudiendo surtirlas todas a la vez"; en realidad no se tenía más agua que "la muy necesaria para las fuentes públicas de la ciudad". Agregaron que si se concedía lo solicitado "se establecería un mal precedente, pues diariamente se presentarían a la Corporación solicitudes en el mismo sentido y habría necesidad de acceder a todas por no haber razón de negar a unos lo que se concedió a otros". Este argumento ignoraba que seis años atrás se había concedido lo mismo a la señora Aldana de Camarena, pero además es interesante subrayar esa percepción de que había muchos vecinos con deseos de tener agua en sus casas $^{43}$.

En 1887, a raíz de una solicitud hecha por Camilo Chávez, la comisión de fuentes y regadíos del Cabildo se mostró muy

41 Pani, 1991, 176. Evidentemente, el autor sobrestima la capacidad de almacenamiento del aljibe de su casa, que con un par de aguaceros se llenaba, pues difícilmente tendría más de veinte metros cúbicos de capacidad.

42 "Solicitud de Martha Aldana de Camarena para tomar de los caños que surten la fuente de la plaza principal una paja de agua para su casa", 18 de marzo de 1871 (AGMA-FH, caja 71, expediente 2).

43 "Solicitud de una paja de agua para una fuente de la casa de Dolores Herrera de Felguérez", 15 de junio de 1877 (AGMA-FH, caja 83, expediente 5). El énfasis es mío. optimista y redactó un proyecto de reglamento para mercedar agua a los particulares. Ello implica que de una política completamente restrictiva, basada en la insuficiencia del agua y el dudoso carácter de los derechos que tenía el Cabildo al manantial del Ojocaliente, se pasó a otra permisiva, que partía del supuesto de que había suficiente líquido y que el Cabildo tenía derechos plenos al agua, circunstancia que le permitía venderla a los particulares.

El proyecto constaba de solo diez artículos y preveía que el ayuntamiento concedería "a las personas que lo soliciten mercedes de agua de la que surte a las fuentes públicas, procedente del 0jocaliente". Se daría una paja de agua por casa habitación (648 Its/ día), a cambio del reconocimiento de un censo de trescientos pesos al $6 \%$ anual, lo que implicaba un rédito de dieciocho pesos anuales. Los interesados se harían cargo de instalar la cañería que abasteciera sus fuentes y de darle el correspondiente mantenimiento, "bajo la inspección y aprobación" del regidor de fuentes y regadíos. Este mismo funcionario vigilaría "que las cañerías se conserven siempre en buen estado, y que los surtidores de agua [...] no sean alterados en su sección de salida", previéndose una multa de cien pesos para el infractor, pudiéndose incluso anular la concesión en caso de reincidencia. Se preveía también que se vendieran "mercedes de agua potable procedente del acueducto llamado El Cedazo", pero ello sucedería solo cuando esa obra "se halle en estado perfecto de reparación" 44.

Hasta donde deja ver la documentación, el pleno del Cabildo actuó en forma prudente, pues en lugar de empezar a vender mercedes quiso asegurarse antes de que hubiera suficiente agua en las cañerías. Para ello le encargó al boticario Pablo de la Rosa y al ingeniero J osé Noriega, muy apreciado por entonces en la ciudad pues acababa de inaugurarse el Teatro Morelos, construido bajo su dirección, que examinaran el manantial del ojocaliente, determinaran "la cantidad de agua" con que se contaba "para todas las fuentes públicas de la ciudad" y si, luego de abastecidas estas, podían hacerse "concesiones" a los particulares. "Después de haber practicado los más minuciosos cálculos" en el manantial "y en la caja repartidora de los Bañitos, de donde se distribuye el agua para las fuentes de la ciudad", los peritos determinaron que el "Ayuntamiento 'posee' actualmente 360 pajas de agua con una corriente uniforme", lo cual quería decir que había agua para abastecer las fuentes públicas y un "sobrante considerable" para mercedarlo a los particulares. En realidad, no sabemos en que consistieron esos "minuciosos cálculos", pero evidentemente ignoraron algo fundamental, el hecho de que el contrato de desamortización de los baños de Los Arquitos establecía que el Cabildo se reservaba solo una naranja, o sea, 144 pajas. Esta era la cantidad de agua que 'poseía' el Cabildo, no las 360 pajas estimadas por los peritos ${ }^{45}$.

44 "Solicitud de Camilo A. Chávez pidiendo dos pajas de agua para sí y para su madre Carmen Moreno de Chávez", 25 de diciembre de 1886 (AGMA-FH, caja 161, expediente 7). El proyecto de reglamento está fechado el 29 de enero de 1887.

45 "Examen de la cantidad de agua con la que cuenta el ayuntamiento para surtir las fuentes públicas", 5 de marzo de 1887 (AGMA-FH, caja 161, expediente 7. 360 pajas de agua $=2 \frac{1}{2}$ naranjas $=162 \mathrm{l} / \mathrm{s}=9.720 \mathrm{~m}^{3}$ por hora $=233.280 \mathrm{~m}^{3}$ por día). 
Y aquí se entraba ya en otro terreno. No se trataba solo del agua aportada por el manantial, ni de la cantidad que llegaba al punto en que se dividía entre los baños y las fuentes públicas, ni siquiera del estado de las cañerías que recorrían la ciudad, sino también de los derechos legales que tenía el Cabildo y de los términos en que se ajustó la desamortización de los baños de los Arquitos y el agua que los abastecía. Es decir, de la cantidad de agua de la que 'legalmente' podía disponer el Cabildo. Por lo visto, De la Rosa y Noriega lo ignoraban, pero no algunos regidores, de manera que cuando este apresurado y endeble "peritaje" fue discutido afloraron esas otras dificultades, que no tenían un carácter técnico, sino jurídico. En realidad, no sabemos si se vendieron a Camilo Chávez las pajas de agua que solicitaba. Parece que no y que habría que esperar todavía doce años para que se resolvieran dos problemas: el técnico, relacionado con la cantidad de agua aportada por el manantial, el desperdicio y el pésimo estado de las cañerías de la ciudad, y el legal, relacionado con el acuerdo entre el ayuntamiento y los dueños de los baños de Los Arquitos, es decir, con la cantidad de agua que podía usar el ayuntamiento para abastecer las fuentes públicas y vender a los particulares interesados.

\section{Aguadores}

La figura del aguador era muy familiar en Aguascalientes durante la segunda mitad del siglo XIX, como lo había sido desde fines de la Edad Media en muchas ciudades peninsulares. En la villa y corte de Madrid llegaron a ser tan numerosos que el Cabildo resolvió en 1653 cobrarles "un canon o matrícula". En general era una actividad desempeñada por individuos de baja extracción social, que "sacaban el agua de los ríos, manantiales fuentes y pozos públicos, con pellejos o cántaros, transportándola a hombros o caballerías" 46 . En Querétaro fueron muy populares desde la época colonial hasta bien entrado el siglo XX; era un oficio humilde, aunque no cualquier persona podía ser aguador, pues el gremio era controlado por el Cabildo, que imponía obligaciones y concedía la necesaria patente. Los aguadores recorrían la ciudad con una placa de metal colgada en el pecho y tenían, entre otras, la obligación de limpiar las fuentes los días primeros de cada mes y la de prestar sus servicios en los casos de incendio ${ }^{47}$.

Entre los aguadores conviene distinguir los que vendían agua para beber, que se aprovisionaban en los manantiales cercanos, y los que se surtían de las fuentes públicas y vendían agua para lavar trastos, regar macetas y otros usos domésticos. En su mayoría, los primeros acudían al ojo de agua Ilamado "Los Negritos", situado unos cinco km al suroeste de la ciudad, muy cerca de donde el río Morcinique se unía al San Pedro, el principal de la jurisdicción ${ }^{48}$. Según Díaz de León, "desde tiempo inmemorial" se consumía en la ciudad ese agua, vendida de casa en casa "por aguadores de oficio", "a tlaco el cántaro", es decir tres centavos

46 Matés, 1999, 134-135.

47 Suárez, 1998, 34.

48 "Mapa del Estado de Aguascalientes levantado de orden del Exmo. Sr. Gobernador Don J esús Terán por Isidoro Epstein, 1857", Mapoteca Manuel Orozco y Berra, Antiguo Arzobispado de Tacubaya, México D.F. (en adelante MOB), 1662A-25.
Imagen 2. Aguador en la pila del jardín de San Marcos

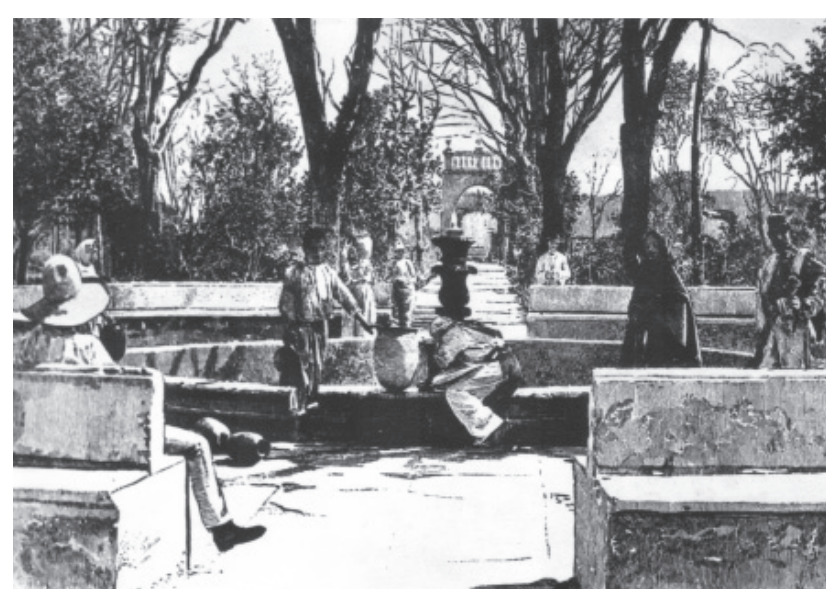

Fuente: Fototeca del AHEA.

por dos cántaros o "seis centavos la carga de cuatro cántaros" 49. Desde primera hora de la mañana se veían en el jardín de San Marcos y otros puntos de la ciudad "aguadores que arrean recuas de asnos con ventrudos cántaros, puestos en jamugas especiales" 50 .

Era frecuente que durante la temporada de lluvias el río San Pedro creciera mucho e impidiera el paso de los aguadores, interrumpiéndose el abasto de "esta agua potable". Según Díaz de León esa dificultad "podía subsanarse fácilmente" si se construía una cañería desde el ojo de agua hasta una explanada que había frente a la estación de los tranvías; de esa manera, si se añadía tan solo una coladera en el nacimiento de la cañería, la ciudad contaría con "agua filtrada y limpia" todo el año $0^{51}$.

Eduardo J. Correa, que nació en Aguascalientes en 1874 y era un agudo observador de las costumbres de la ciudad, redactó una sugestiva "viñeta" del aguador de Los Negritos. Lo recuerda lanzando sus "redundantes" pregones "por las calles desiertas", anunciando su agua "zarca y azul" que se zangoloteaba en los cántaros colgados de sus bestias. Cuando se abría la puerta de un zaguán el vendedor detenía sus burros y tomaba "dos cántaros porosos, uno bajo la axila y con otro en la mano"; uno lo vaciaba en la "ventruda tinaja" que había en la cocina y otro en la "destiladera" de cantera del comedor. Era una delicia ver "el agua transparente" irisada por la luz y escuchar el "gluglú" que desgranaba "cadencias de sonrisas". Después de cobrar, el aguador regresaba a buen trote a la calle, azotaba a sus burros e interrumpía la canícula con sus gritos: " ¡Agua zarca y azul, agua de Los Negritos!" Según Correa, "tan solo dos centavos vale la mercancía", o sea un centavo cada cántaro de agua, menos de lo que consigna Díaz de León (tres centavos por dos cántaros) ${ }^{52}$.

En 1887, en el contexto de la investigación sobre una cañería hecha por un particular para aprovechar las aguas de Los Negritos en su huerta, un empleado municipal observó que el manantial "no tiene brocal ni cerca", a consecuencia de lo cual estaba "bastante sucio, porque en él se mean los burros de [los] agua-

\footnotetext{
49 Díaz de León, 1892, 205. Delgado, 2011, 76, 259.

50 Correa, 1937, 45.

51 Díaz de León, 1892, 205.

52 Correa, 1945, 111.
} 
dores que [lo] explotan". Se acordó exigir a los aguadores que "contribuyan a formar un fondo para [hacerle] un brocal o cerca de cuatro o cinco varas de circunferencia, para que se conserve siempre limpio y aseado, a beneficio del público" ${ }^{53}$. La obra se Ilevó a cabo, aunque al parecer a cargo del municipio, que "aprobó el gasto necesario para cercar de cal y canto el manantial de agua potable de Los Negritos, que es la mejor que consume la población". De cualquier manera, puede inferirse que ese agua no era tan "transparente" como pretende Correa en su bucólica recreación ${ }^{54}$. Por otra parte, había aguadores que vendían agua para beber tomada supuestamente del manantial de Los Negritos, pero que en realidad Ilenaban sus cántaros "con agua del río" ${ }^{55}$, como sucedía en la vecina Zacatecas, donde los aguadores vendían agua que tomaban del arroyo en el que "se descargaban todos los caños y albañales de la ciudad" 56. Los habitantes del norte de la ciudad -sobre todo el barrio de Guadalupe, que se desarrolló con fuerza desde la apertura de la Gran Fundición Central Mexicana (1895) - eran abastecidos por aguadores que llenaban sus cántaros en unos ojos de agua ubicados en el curso del arroyo de Los Arellano, en tierras de la hacienda de Las Trojes. En noviembre de 1891, 32 aguadores se quejaron acremente del señor J esús Díaz Infante, que acababa de comprar esa hacienda y les impidió tomar agua, asumiendo que los manantiales le pertenecían. Los aguadores argumentaron que "esos ojos de agua zarca no son obra del hombre", que la servidumbre de la que hacían uso era "legal" y beneficiaba a "todos los habitantes de la ciudad" y que los anteriores propietarios de esos terrenos jamás habían entorpecido su trabajo.

En forma "intempestiva y violenta, valiéndose de sus sirvientes", Díaz Infante les había negado el acceso a los manantiales, e incluso había "remitido presos" a los que no acataron su orden. El j efe político había reconvenido a Díaz Infante, pero este ignoró su petición, y lo mismo hizo después con un "mandato" que le hizo llegar el regidor del ramo de regadíos. Los aguadores alegaban que tanto el arroyo como los manantiales eran "de propiedad pública y de uso común", por lo que no podía estorbarse ni prohibirse su uso. El ayuntamiento, en su carácter de "legítimo representante del pueblo", debía tomar cartas en el asunto, lo que al parecer hizo ${ }^{57}$.

Aparte de los que vendían agua para beber había un gran número de aguadores que trabajaban acarreando agua de las fuentes públicas a los domicilios particulares. Basado en un "padrón antiguo", Díaz de León compuso un "Cuadro estadístico de las profesiones, oficios y ocupaciones a que se dedican los habitantes de Aguascalientes", según el cual había diecinueve aguadores en la ciudad ${ }^{58}$. La cifra parece razonable para una ciudad que en

53 "Solicitud de Paulino Durón pidiendo se le remate el agua sobrante del manantial de Los Negritos para cultivar legumbres en un terreno", 22 de noviembre de 1887 (AGMA-FH, caja 137, expediente 41).

54 Correa, 1945, 111, 173.

55 "Aguadores. Cuidado con ellos", El Correo del Centro, Aguascalientes, 10 de mayo de 1896.

56 Alfaro, 2013, 96

57 "Ocurso de 32 aguadores quejándose de que Jesús Díaz Infante les ha prohibido tomar agua de los pozos de los Arellano", 9 de noviembre de 1891, AGMA-FH, caja 198, expediente 31.

58 Díaz de León, 1892, 229. Delgado, 2011, 76, 259.
Imagen 3. El aguador de Claudio Linati

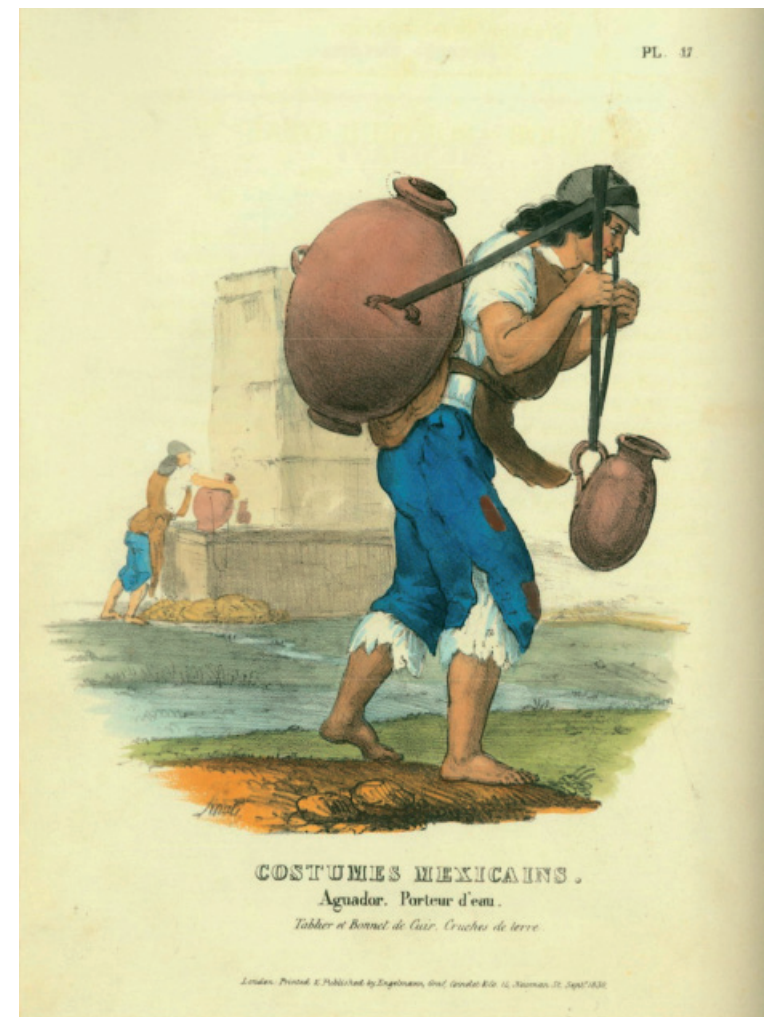

Fuente: Linati, 1955, lámina 17.

1891 tenía 22 fuentes públicas y unos treinta mil habitantes, pero en un registro municipal que abarca el periodo 1895-1899 se da el nombre de un total de 339 aguadores, un número asombroso, que sugiere que en cada fuente había por lo menos una docena de aguadores ${ }^{59}$, disputándose una clientela más bien escasa. Tal vez cualquiera podía instalarse con sus botes o cántaros junto a una fuente y ofrecer sus servicios, pero si observamos con cuidado el registro advertimos que se trata de todos los que se inscribieron entre 13 de julio de 1895 y el 2 de diciembre de 1899, no los que en algún momento se mantenían activos. Incluso hay aguadores de los que se dice que "se retiraron del oficio" y alguno cuya patente se dejó "sin efecto por ladrón" 60.

En cualquier caso, se trataba de hombres fuertes y curtidos, como los que retrató Linati en 1828, capaces de llevar dos pesados cántaros de barro llenos de agua, sesenta kilos o tal vez más en total, pues el recipiente era tan pesado o más que el líquido. Aunque el "portador de agua" de Linati era un poco diferente, pues descansaba sobre sus espaldas un enorme cántaro principal de forma esférica, al que hacía contrapeso otro mucho más pequeño que colgaba de su frente y que seguramente servía para medir el agua que despachaba a sus clientes. Inmovilizado por las correas, el aguador de Linati "camina recto hacia adelante sin permitirse el menor movimiento de cabeza" 61 .

59 Según Alfaro $(2013,97)$, en 1887 Zacatecas tenía 40.000 habitantes y 120 aguadores.

60 AGMA-FH, caja 213, expediente 31

61 Linati, 1956, lámina 17. 
En su viñeta del "aguador de la ciudad", Correa le pone nombre y apellido, lo que implicaría que se trata de un personaje conocido y hasta apreciado, no uno entre varios cientos, sino entre un par de docenas. Cada fuente tendría su aguador, dos a lo sumo. Correa los recuerda "con un palo en el hombro, de cuyas puntas penden dos cubos de hoj alata". Haciendo equilibrio, "con oscilante paso" y los brazos extendidos "sobre el madero", el aguador iba y venía entre la pila donde llenaba sus botes y el domicilio en el que los vaciaba, cobrando "un centavo por viaje". El aguador que recuerda Correa se llamaba Remigio González y trabajaba en la pila del Obrador, a una cuadra de la plaza principal. Había casas en las que entregaba hasta "ocho viajes" de agua, "porque tienen su patio repleto de macetas y un lavadero grande con dos hondas piletas", o porque era la casa del alcaide de la cárcel, "que les lava a los presos", o sencillamente porque sus dueños eran ricos "y tienen muchos pesos", como los Arellano o los Camarena. En general, el servicio se daba a las casas "donde no tienen pozo" y el agua era empleada "para regar las plantas, para limpiar los suelos, para dejar cual nieve sábanas o pañue-

Imagen 4. El aguador, haciendo equilibrio, "con oscilante paso", los brazos extendidos "sobre el madero"

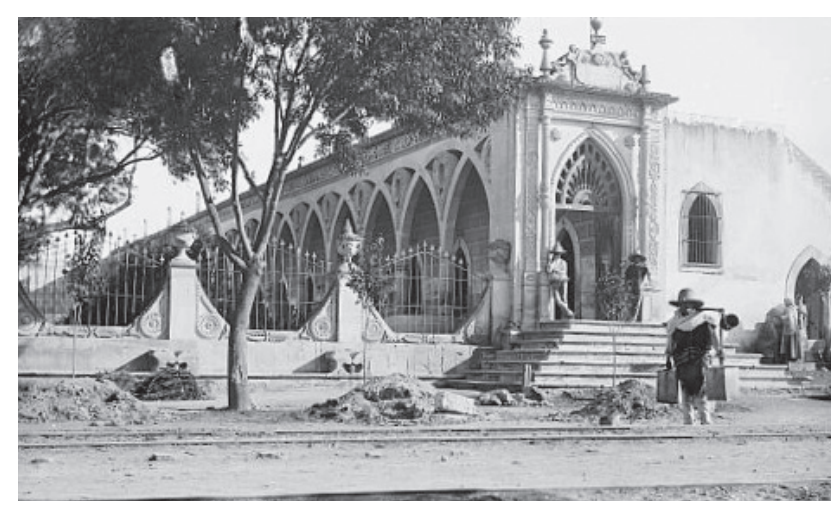

Fuente: Fototeca del AHEA.

los". Entre un viaje y otro el aguador descansaba un poco junto a la pila, gozando "el hechizo de las encantadoras que ocasionalmente hacen oficios de aguadoras", como la que pintó Goya; mientras colocaban sus cántaros en el brocal y esperaban a que se llenaran, estas mozas, "aguadoras improvisadas", alegraban "el paso de las horas" con sus risas y cotilleos. Pero cuando llovía el aguador se quedaba sin trabajo, pues en todas las casas las canaletas vomitaban agua "a raudales", que era recogida "en ollas y vasijas". Remigio González y todos los de su oficio le pedían entonces al señor del Encino que el sol saliera de nuevo y luciera "su carro diamantino", porque mientras no dejara de llover estaban atenidos a "la pía caridad" de sus patrones para "lograr el pan de cada día"62.

\section{Crisis del sistema de abasto en línea}

Durante la segunda mitad del siglo XIX, conforme creció la ciudad y se extendieron las nuevas ideas sobre la higiene pública,

62 Correa, 1945, 97-98. íntimamente asociadas a la disponibilidad de agua, se multiplicaron las quejas sobre el pésimo estado de las acequias, la insuficiencia del agua proveída por las fuentes públicas y la necesidad de modificar radicalmente el esquema que regulaba el abasto urbano. El problema era grave y constituía un secreto a voces, pero se carecía de los recursos necesarios para emprender una reforma integral del sistema. El Cabildo era consciente del problema, pero su pobreza era proverbial; en el seno del gobierno del estado, donde había un poco más de dinero, se pensaba que el problema debía ser resuelto a nivel del Cabildo, circunstancia que tenía por consecuencia una especie de círculo vicioso.

Podemos decir que el sistema de abasto de agua en línea, que Matés Ilama "sistema clásico de agua potable", propio de las sociedades preindustriales ${ }^{63}$, hizo crisis en Aguascalientes en 1883, cuando la compañía del Ferrocarril Central Mexicano construía a toda prisa la línea troncal que uniría la ciudad de México con Paso del Norte y se sabía que la ciudad estaba beneficiada por el trazo de las vías. El Cabildo consideró necesario practicar mejoras "dignas del buen nombre" de la ciudad "y de la ilustración de sus habitantes", en particular "componer la acequia principal de regadíos", formando "una calzada desde la acequia de la cuadra donde empieza la finca de los baños de Los Arquitos, hasta donde se ponga la estación del Ferrocarril Central, por ser esta mejora muy necesaria, tanto para el ornato de la población como para la comodidad en el tráfico"64. No se hizo gran cosa por entonces, pero la compañía del Central emergió como un poderoso actor de la vida económica y social de la localidad, demandando diversos apoyos y concesiones, en particular el derecho de usar grandes cantidades de agua tomada de la acequia que abastecía los baños de los Arquitos y las fuentes públicas de la ciudad ${ }^{65}$.

En 1889 se le pidió al ingeniero H. M. Blake, vecino de la ciudad de Guadalajara, un proyecto para entubar con cañería de fierro el agua del Ojocaliente, tanto la que abastecía las fuentes públicas como la que daba riego a las huertas, el cual se pensaba que podía fondearse vendiendo mercedes de agua a particulares $^{66}$. El gobernador Alejandro Vázquez del Mercado (1887-1895) consideró la posibilidad de construir una presa que retuviera las aguas del manantial y permitiera regular en forma adecuada el riego de las huertas y el abasto de agua potable para la ciudad ${ }^{67}$. El médico J esús Díaz de León, que lo admiraba sin disimulo, escribió que "felizmente nuestro actual gobernador se ha ocupado seriamente en este asunto", permitiendo que "pronto" se organiza-

63 Matés, 1999, 37 y ss.

64 "Excitativa del Gobierno del Estado para que el Ayuntamiento de la capital se ocupe con oportunidad de procurar mejorar las actuales condiciones de la ciudad poniéndola a la altura de la ilustración de sus habitantes, con objeto de esperar la inauguración del Ferrocarril Central que no tardará en llegar", 23 de diciembre de 1882 (AGMA, FH, caja 15, expediente 23).

65 "Solicitud del Ferrocarril Central para tomar la mitad del agua que corre por el acueducto descubierto que sale del manantial de 0jocaliente", 25 de febrero de 1882 (AGMA-FH, caja 11, expediente 34); "Permiso concedido al Ferrocarril Central para que tome agua de la acequia pública por quince días para sus máquinas", 22 de agosto de 1891 (AGMA-FH, caja 185, expediente 19).

66 AGMA-FH, caja 230, expediente 36: "Se refiere a pedir al Sr. Antonio Chávez, devuelva al archivo el expediente № 54 del año 1889. Proyecto de entubación de aguas públicas", 31 de mayo de 1897. Martínez Delgado, 2009, 152.

67 AGMA-FH, caja 227, expediente 25, Informe del presidente municipal Ignacio A. Ortiz, 16 de septiembre de 1896. 
ra una empresa encargada de la construcción de la presa, la cual permitiría regar con suficiencia las huertas de la ciudad, "aun suponiendo que se planten otras tantas de las que tenemos" 68 . Sin embargo, estas esperanzas fueron completamente defraudadas, pues nunca se formó la mencionada empresa ni mucho menos se acometió la construcción de la presa.

Por su cuenta, algunos particulares hicieron propuestas razonables desde el punto de vista técnico y económico, pero políticamente inviables. En octubre de 1886, el señor Pascual Serrano, dueño de la hacienda de Ojocaliente, en la que nacía el manantial y por la que corrían las acequias hasta su entrada a la ciudad, expresó su deseo de "organizar una compañía que tenga por objeto el fomento de los regadíos en esta ciudad". Su proyecto consistía en construir "tres o cuatro" represas pequeñas en el curso del arroyo del Cedazo, utilizar los "depósitos" o charcos que había "por el lado de la Alameda" y aumentar con ello la descarga de agua en las acequias que abastecían las huertas y las fuentes públicas de la ciudad. Según él, con esta sencilla solución a las huertas no les faltaría el riego, "especialmente en los meses de abril y mayo", los más duros del estiaje, y los hortelanos podrían emprender el "cultivo de verduras y plantas delicadas", Io que no podían hacer debido a que se les daba riego cada sesenta o más días. Además, al quedar el último de los depósitos que se construirían en el arroyo del Cedazo al mismo nivel que el viejo acueducto que llevaba agua al barrio de Triana, se obtendría un "bien inestimable", "enteramente accesorio a la empresa" pero "muy digno de ocupar por sí solo la atención" del Cabildo, pues los vecinos de ese barrio tendrían "agua potable todo el año y no unos cuantos meses, como ahora sucede". Para llevar a buen término su empresa, juzgaba necesaria la "cooperación" del Cabildo y, en concreto, le pedía usar el agua del manantial del Ojocaliente "que se desperdicia", usar las acequias existentes "y abrir nuevas donde no las haya" y obtener otros auxilios que no perjudicaran los intereses municipales. Todo lo justificaba el fin de la empresa, que era "aumentar los regadíos y el agua potable para la población"69.

En su respuesta, el Cabildo reconoció que el agua que corría por las acequias no bastaba para cubrir los requerimientos de las huertas, pero añadió que junto con el gobierno del estado estudiaba la manera de evitar el colapso de "ese elemento de vida, que ayuda de una manera principal a las clases necesitadas de esta localidad". Se aludía también a ciertos esfuerzos "para reunir los elementos de los horticultores a los que podía tener la Corporación con objeto de emprender la reforma o reparación de las acequias" y a la indiferencia de los convocados, que dejaron "transcurrir el tiempo sin comprender sus propios intereses", provocando que, ante la carencia de recursos en las arcas del erario municipal, no se hubiera podido hacer una "reforma completa" del sistema, sino tan solo la "reparación parcial de las acequias". A fines de 1895 se seguía discutiendo la propuesta de Pascual Serrano, pero para entonces ya se sabía que el goberna-

68 Díaz de León, 1892, 246.

69 AGMA-FH, caja 109, expediente 10, "Ocurso de Pascual Serrano sobre organizar una compañía que tenga por objeto el fomento de los regadíos de esta ciudad, así como el aumento del agua potable del Cedazo", 23 de octubre de 1886. dor Rafael Arellano, que estaba iniciando su gestión, maduraba "un proyecto de construcción de acequias para regadíos y reforma de la calzada del 0jocaliente", Io que desaconsejaba celebrar un contrato con un particular ${ }^{70}$.

Lo cierto es que el sistema de abasto de agua para las huertas y las fuentes públicas de la ciudad era un desastre. La acequia que conectaba el manantial del Ojocaliente con los baños de los Arquitos perdía muchísima agua, pero ni siquiera se sabía cuánta, pues nunca había sido calculado el gasto del manantial ni la que recibían los baños. Según el contrato de desamortización, su mantenimiento correspondía a los dueños de los baños, pero estos nunca habían tenido ni dinero ni interés en el asunto, pues les bastaba con que hubiera una cantidad razonable de agua en sus cuartos de baño y piscinas. El camino del ojocaliente, que en algún momento había sido descrito como un "hermoso paseo" lleno de árboles que formaban "verdes embovedados" que filtraban con gracia la luz del sol y volvían delicioso el lugar ${ }^{71}$, estaba convertido por el descuido de muchos años en un "pantano" 0 muladar intransitable, donde lo más visible eran las raíces podridas de los árboles ${ }^{72}$.

\section{Tiempos nUeVos, PROBLemas VIEj OS}

En conclusión, podemos decir que, en 1895, cuando el régimen porfiriano entraba en su etapa de plena madurez, el problema del abasto de agua potable en la ciudad de Aguascalientes era tan grande que exigía una intervención mayor y muy costosa, poniéndola lejos del alcance del Cabildo, que en teoría debía hacerse cargo de las obras pero que no contaba con los recursos necesarios. Algo parecido sucedía en Córdoba, Veracruz, pero en este caso los encargados de los estudios técnicos recomendaron la participación de capitalistas privados, pues ello volvería "más perfecta y económica la ejecución [del] proyecto". En Culiacán, San Luis Potosí, Villahermosa, Monterrey, Torreón, Tampico y otros lugares empezaron a formarse compañías privadas con el propósito de especular con el abasto urbano de agua potable $e^{73}$. En Guadalajara, por el contrario, las costosas obras hechas con el propósito de llevar agua a la ciudad desde los manantiales de Los Colomos, fueron costeadas por el gobierno del estado ${ }^{74}$.

Al igual que en J alisco, el gobernador de Aguascalientes, Rafael Arellano, decidió en diciembre de 1895 que el ejecutivo a su cargo podía e incluso debía enfrentar el problema en la capital del estado. Luego de diagnosticar que la acequia y el acueducto del Ojocaliente "se encontraban en un estado de deterioro lamentable", ordenó su reconstrucción, al tiempo que se limpiaban los manantiales y se reformaba la "defectuosa calzada" que comunicaba la ciudad con los antiguos baños del Ojocaliente. En los términos de la negociación ajustada con la propietaria de los baños de Los Arquitos, la reconstrucción de la acequia se tradujo en una elevación sustancial del volumen de agua del que disponía

70 La respuesta del Cabildo, fechada el 30 de enero de 1896, en Idem.

71 "Noticias estadísticas del Departamento de Aguascalientes", 179-180.

72 El Eco Social, Aguascalientes, 8 de junio de 1894.

73 Birrichaga, 1998, 197, 223-224.

74 Torres, 2013, 339-347. 
el Cabildo, lo cual, a su vez, implicó la posibilidad de mercedar agua a los particulares. Para ello fue necesario entubar el agua potable desde la nueva caja repartidora hasta la plaza principal de la ciudad, las fuentes públicas y las casas de los particulares interesados. Todas las obras fueron ejecutadas durante la gestión del gobernador Arellano, entre diciembre de 1895 y noviembre de 1899. Técnica y financieramente puede decirse que las obras constituyeron un éxito rotundo, lo que permitió que la ciudad de Aguascalientes transitara del viejo sistema de abasto en línea al nuevo sistema de abasto en red, propio de la era industrial ${ }^{75}$.

Pero quisiera terminar mi artículo con algunas referencias a los aguadores, que son el eje alrededor del cual gira este número monográfico de la revista Agua y Territorio. Suele afirmarse que la Revolución de 1910 afectó radicalmente al país, trazando un antes y un después, pero se disimula el hecho de que muchas tradiciones fuertemente arraigadas en la vida colectiva sobrevivieron al vendaval, sin que se vieran afectadas ni mucho menos desterradas por los embates modernizadores del nuevo régimen. Ninguna revolución, ni siquiera la francesa de 1789, es capaz de "borrar todas las huellas de su existencia previa"; "sin importar qué tan violenta o utópica sea su naturaleza", las revoluciones "no crean mundos nuevos de la nada", sino que lo hacen "con los materiales que espigan del viejo régimen", "elementos de continuidad que están insertos en la materia que compone las instituciones y adheridos dentro de la conciencia colectiva" 76. En la ciudad de Aguascalientes, por ejemplo, mucha gente siguió usando las acequias para bañarse y lavar la ropa, e incluso como drenaje. En 1945 se denunciaba que la acequia de la calzada Arellano era "una de las más concurridas por las clases populares", que la usaban como "baño público"; esa costumbre era odiosa y "desdice mucho del nivel cultural de una capital de estado", pero al parecer nada podía hacerse para desterrarla. Abundaban también "las tomas clandestinas" de agua y los que se valían de su toma (legal) para vender o regalar agua a sus vecinos, habiendo incluso alguno que golpeaba a las personas que "no le pagan" y tiraba "sus botes con agua". En 1930, en el contexto de su ofensiva higienista, el Cabildo ordenó la demolición de la pila del Obrador, algo que -como era previsible-fue censurado en tono lastimero por algunos que recordaban haber mitigado su sed de niños en "las aguas cristalinas" de esa fuente ${ }^{77}$.

También sobrevivieron los aguadores, que formaban un gremio bien conocido aunque informal. En 1925 el gobierno municipal decidió cobrarles un impuesto, a lo que se opusieron sin éxito. Enseguida se nombró un inspector para "vigilar la conducta de todos los aguadores", asegurarse de que portaran su "patente" y mantuvieran limpias las fuentes públicas. Como dice Delgado, la permanencia de este oficio se explica por las "limitaciones de la red de abasto", pero también porque mucha gente seguía prefiriendo el agua del manantial de Los Negritos, que en casa se pasaba "a través de un filtro de cantera porosa", tal como recordaba Correa. Atendiendo la creciente demanda se empezó a vender

75 Por razones de espacio es imposible abundar sobre este tema, al que he dedicado un artículo (Gómez, 2016).

76 Darnton, 2014, 425, 543.

77 Delgado, 2011, 285-289. como potable agua llevada de los manantiales de San Lorenzo, San Ignacio y Sandovales, muy cercanos a la ciudad. Filtrada o por lo menos refrescada en una tinaja de barro resultaba muy agradable, pero los jóvenes ingenieros de la ciudad, empeñados en su cruzada higienista, denunciaban que eran aguas "contaminadas". Durante mucho tiempo, hasta bien entrada la segunda mitad del siglo XX, la gente se mantuvo fielmente aferrada a la idea de que el agua de los manantiales del Ojocaliente, que llegaba a las casas a través de la red pública de abasto, sabía mal y era "nociva para la salud"; todos los que podían se daban el lujo de comprar agua embotellada para beber y usarla en la cocina ${ }^{78}$.

En agosto de 1945 se reportó en un diario que justo por esas fechas empezaba a circular -otro signo de la modernizaciónque en la ciudad habían aparecido aguadores que llevaban sus cántaros y garrafones ya no en burros, sino en "en carritos tirados por acémilas" que rodaban sobre viejas Ilantas Goodrich; según el autor de la nota, ese agua era insalubre, pero los habitantes de la ciudad la consumían con avidez, lo que provocaba "frecuentes tifoideas". Como hace notar Delgado, más allá de la discusión sobre la potabilidad del agua, la noticia era el surgimiento de pequeñas compañías que estaban desplazando al viejo gremio de los aguadores. La más estable y exitosa era la de J uan Muñoz, que se abastecía de un pozo alimentado por el manantial de San Lorenzo ${ }^{79}$.

El agua San Lorenzo era la preferida por los consumidores y se creía que era completamente potable, pero el dueño de esa negociación tuvo que enfrentar otros problemas. Uno en concreto con los habitantes de J esús María, que alegaban que ese agua procedía de un pozo alimentado por el manantial que daba de beber al pueblo. Hubo al parecer algunos disturbios y se llegó a impedir la salida de los carros repartidores, ocasionando que el abasto disminuyera "en forma considerable". En una ocasión "un grupo de personas armadas con palos y cuchillos" asaltó un carro y amenazó a su conductor. Los vecinos de J esús María decían que se extraían diariamente veinticuatro mil litros del pozo, lo que había provocado que el rendimiento de su manantial disminuyera de forma alarmante, pero el dueño del negocio sostenía que solo sacaba ocho mil litros diarios y que "la escasez de agua en el pueblo obedecía al estado deficiente de las bombas y tanques del sistema de abasto" 80 .

Como puede verse en diversas fotografías de la época, esta empresa contaba por lo menos con una docena de carros, equipados con un tambo metálico que tendría unos mil litros de capacidad (un metro cúbico). Los conductores lucen en su mayoría sencillas ropas de campesinos, pero se ven algunos vestidos de traje y sombrero Stetson, mejor ajustados a la novedad del servicio. En la parte delantera de los carros puede verse un pequeño bote de hojalata, con el que se medía y despachaba el líquido.

La modernización y ampliación del servicio eran evidentes de muchas maneras, pero los problemas eran viejos. En 1887 se había denunciado que los burros de los aguadores se orinaban en

78 Ibidem, 291-292.

79 El Sol del Centro, Aguascalientes, 8 de agosto de 1945, citado por Delgado, 2011, 292-293.

80 Delgado, 2011, 294-296. 
el manantial de Los Negritos, cuyas aguas zarcas bebían con agrado muchas familias. De manera parecida, sesenta años después los empleados de los Servicios Sanitarios descubrieron que el pozo ubicado en el rancho Sandovales - del que se tomaba agua que se vendía como apta para su consumo en la ciudad-estaba sucio y "lleno de cieno"; con la autoridad que le daban sus guantes y su bata blanca, un funcionario prohibió la venta de esas aguas. En seguida, los cruzados de la higiene visitaron el pozo de la empresa San Lorenzo y observaron un panorama igualmente desolador; no mencionaron que los burros que tiraban los modernos carros tuvieran problemas de incontinencia, como antaño los que llevaban los aguadores al manantial de Los Negritos, pero tuvieron la precaución de ordenar a los concesionarios de ese servicio que higienizaran el lugar y que purificaran con cloro el agua que vendían. Aún más, con el propósito de disipar cualquier duda, el médico a cargo de esas inspecciones se comprometió a realizar en el laboratorio "minuciosos análisis para determinar la mayor o menor pureza de dichas aguas".

En un principio se divulgó la noticia de que todas esas aguas estaban contaminadas y no eran aptas para su consumo, pero al final, tal vez por razones de conveniencia práctica, se determinó que los manantiales de Sandovales y San Lorenzo daban aguas "absolutamente potables", que por desgracia se contaminaban en los carros en que eran llevadas a la ciudad. El médico a cargo

\section{Imagen 5. En 1945 aparecieron en la ciudad estos "modernos" carros} repartiendo agua de San Lorenzo

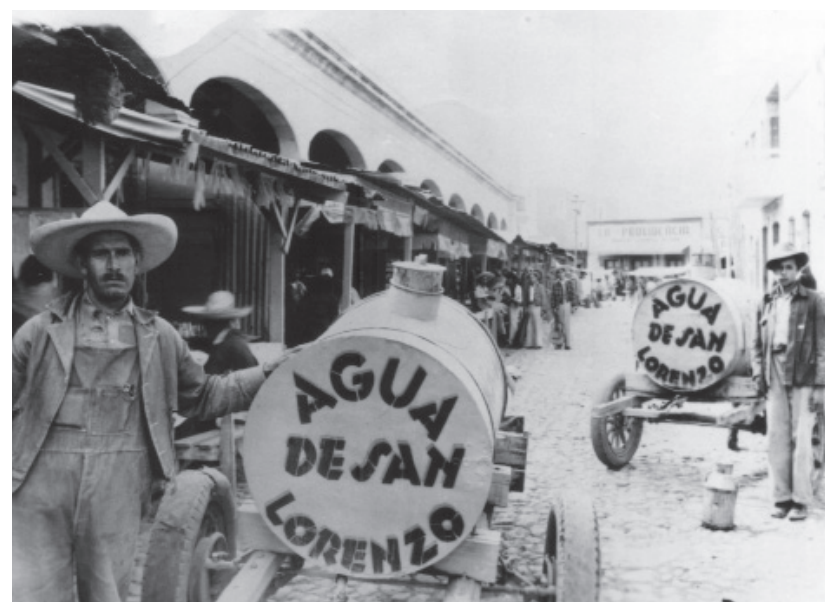

Fuente: Fototeca del AHEA.

de la oficina de los Servicios Sanitarios autorizó su venta, con la única condición de que se purificaran con cloro, "ya que después de pasar por tal acto químico serán absolutamente inocuas para el consumidor" ${ }^{81}$.

Sin saberlo, con pequeñas variantes en el libreto, las empresas que vendían agua "potable" en la ciudad y la oficina encargada de certificarlas estaban poniendo en escena una obra bien conocida en Aguascalientes, en cuyas calles seguía oyéndose el viejo pregón: "¡Agua zarca y azul"!

81 Reportajes publicados en El Sol del Centro, Aguascalientes, 15, 18, 19, 25, 26 y 27 de mayo de 1946, citados por Delgado, 2011, 297-298.

\section{Bibliografía}

Aboites, L. 1998: El agua de la nación. Una historia política de México (1888-1946). México, CIESAS.

Agostoni, C. 2005: "Las delicias de la limpieza: la higiene en la ciudad de México", en Staples, A. (coord.): Historia de la vida cotidiana en México, tomo IV: Bienes y vivencias. El siglo XIX. México, FCE-El Colegio de México, 563-597.

Alfaro, E 2011: "La ciudad en torno al agua. El arroyo de la Plata como eje simbólico en el ordenamiento urbano de Zacatecas", tesis doctoral, El Colegio de Michoacán, Zamora.

Alfaro, E. 2013: "El abastecimiento de agua: Un problema urbano sin solución (Zacatecas, México, siglo XIX)", en Agua y Territorio, 1, Jaén, 91-102. D0l: https:// dx. doi. org/10.17561/at. vli1. 1037

Birrichaga, D. 1998: "Las empresas de agua potable en México (18871930)", en Estela Suárez, B. (coord.): Historia de los usos del agua en México. Oligarquías, empresas y ayuntamientos (1840-1940), México D. F., CIESAS-IMTA-Comisión Nacional del Agua, 181-221.

Birrichaga, D. (coord.) 2007: La modernización del sistema de agua potable en México 1810-1950. México, El Colegio Mexiquense.

Camacho Altamirano, H. 2007: "Nuevos significados del agua en la ciudad de San Luis Potosí (1900-1916)", en Birrichaga, D. (coord.): La modernización del sistema de agua potable en México 1810-1950. México, El Colegio Mexiquense, 125-152.

Camacho Pichardo, G. 2007: "Las fuentes de agua en la ciudad de Toluca (1824-1850) o de cómo se introdujo el agua a las casas: ihigiene 0 confort?", en Birrichaga, D. (coord.): La modernización del sistema de agua potable en México 1810-1950. México, El Colegio Mexiquense, $59-76$.

Castañeda, R. 1998: "Esfuerzos públicos y privados para el abasto de agua a Toluca (1862-1910)", en Suárez Cortez, Blanca E. (coord.): Historia de los usos del agua en México. Oligarquías, empresas y ayuntamientos (1840-1940). México, D. F. CIESAS-IMTA-CNA, 105-175.

Castañeda, R. 2007: "Higiene o negocio. Cambio y protesta social en relación con el sistema de abasto de agua en Toluca (1830-1880)", en Birrichaga, D. (coord.): La modernización del sistema de agua potable en México, 1810-1950. México, El Colegio Mexiquense, 77-100.

Correa, E. J. 1937: Un viaje a Termápolis. Óleos antiguos. México, Ediciones Botas.

Correa, E. 1945: Viñetas de Termápolis. Renglones rimados. México, edición del autor.

Darnton, R. 2014: El diablo en el agua bendita o el arte de la calumnia de Luis XIV a Napoleón. México, Fondo de Cultura Económica.

Dávila, L. E. 1985: La desamortización y nacionalización de bienes eclesiásticos y de corporaciones civiles. Aspectos económicos y sociales. Aguascalientes (1856-1875). Aguascalientes, reporte de investigación, CIRA.

De la Mota, A. 1966: Descripción geográfica de los reinos de Nueva Galicia, Nueva Vizcaya y Nuevo León. México, Instituto J alisciense de Antropología e Historia.

Delgado, F. J. 2011: "Obra pública, cambio urbano y protesta social en la primera mitad del siglo XX. El abasto de agua en la ciudad de Aguascalientes", tesis doctoral, El Colegio de México, México.

Díaz de León, J. 1892: "Apuntes para el estudio de la higiene de Aguascalientes", en Vázquez del Mercado, A.: Memoria que sobre los diversos ramos de la administración pública presenta a la Honorable Legislatura el ciudadano Alejandro Vázquez del Mercado, gober- 
nador constitucional del Estado de Aguascalientes, por el periodo de primero de diciembre de 1887 a 30 de noviembre de 1891. Aguascalientes, Tipografía de J esús Díaz de León a cargo de Ricardo Rodríguez Romo, 177-248.

Dublán, M. y Lozano, J. M. 1876-1912: Legislación mexicana o Colección completa de las disposiciones legislativas expedidas desde la independencia de la república. México. Disponible en internet: http:// www. biblioweb.tic. unam. $\mathrm{mx} /$ dublanyl ozano/

Epstein, I. 1861: Cuadro Sinóptico de Aguascalientes. Aguascalientes, Tipografía de Ávila y Chávez.

Estadísticas sociales del Porfiriato, 1877-1910. México, Dirección General de Estadística de la Secretaría de Economía. Disponible en internet: http:// www. inegi. org. mx/ prod serv/ contenidos/ espanol/ bvinegi/ productos/ integracion/ pais/ historicas/ porfi/ ESPI. pdf

Gómez, J. 2014: "El abasto de agua en la villa de Aguascalientes. El acueducto del Cedazo, 1731-1891", en Tzintzun, 59, 13-52.

Gómez, J. 2014a: "Los orígenes del sistema de huertas en Aguascalientes. Un análisis a partir del título de composición de 1644", en Investigación y ciencia, 63, 40-57.

Gómez, J. 2016: "La construcción del primer sistema de abasto de agua en red en la ciudad de Aguascalientes, 1896-1899", en Secuencia, 96, 107-141. Dol: http:// dx. doi.org/ 10.18234/ secuencia. v0i96. 1407

González, A. 1881: Historia del Estado de Aguascalientes. México, Librería, Tipografía y Litografía de V. Villada.

Goubert, J. P. 1989: The Conquest of Water: The Advent of Health in the Industrial Age. New J ersey, Princeton University Press.

Hale, Ch. A. 1972: El liberalismo mexicano en la época de Mora, 18211853. México, Editorial Siglo XXI.

Iracheta, M. 2007: "Del agua de los religiosos a la del ayuntamiento: el proceso de secularización en Toluca (1814-1861)", en Birrichaga, D. (coord. ): La modernización del sistema de agua potable en México 1810-1950. México, El Colegio Mexiquense, 23-58.
Linati, C. 1956: Trajes civiles, militares y religiosos de México. México, UNAM.

Loreto, R. 2010: Agua, piel y cuerpo en la historia cotidiana de una ciudad mexicana. Puebla, siglos XVI-XX. Puebla, Ediciones de Educación y Cultura-BUAP.

Martínez Delgado, G. 2009: Cambio y proyecto urbano. Aguascalientes, 1880-1914. Aguascalientes, UAA-Pontificia Universidad J averiana de Bogotá-Fomento Cultural BANAMEX.

Matés, J. M. 1999: La conquista del agua. Historia económica del abastecimiento urbano. J aén, Universidad de J aén.

Matés, J. M. 2013: "La conquista del agua en Europa: los modelos de gestión (siglos XIX y XX)", en Agua y Territorio, 1, 21-29. D0I: https:// dx. doi.org/ 10.17561/ at. v1i1. 1030

Medina, T. 1900: "Plano de la ciudad de Aguascalientes formado por el ingeniero Tomás Medina Ugarte por disposición del Gobierno del Estado, año de 1900". Mapoteca del AHEA.

"Noticias estadísticas del Departamento de Aguascalientes correspondientes al año de 1837. Primer cuadro estadístico del Departamento de Aguascalientes", en Boletín de la Sociedad Mexicana de Geografía y Estadística, México, 1, 9, febrero, 1850, 179-180.

Pani, A. 1991: Tres relatos de sabor antiguo. Aguascalientes, ICA.

Suárez, B. E. 1998: "Poder oligárquico y usos del agua: Querétaro en el siglo XIX (1838-1880)", en Historia de los usos del agua en México. Oligarquías, empresas y ayuntamientos (1840-1940). México, IMTACIESAS-Comisión Nacional del Agua, 15-103.

Suárez, B. E. y Birrichaga, D. 1997: Dos estudios sobre usos del agua en México (siglos XIX-XX). México, IMTA-CIESAS.

Torres Rodríguez, A. 2013: "Infraestructura hidráulica en Guadalajara para el abastecimiento de agua potable: el caso de sustentabilidad en las galerías filtrantes de Guadalajara", en Relaciones, 136, 317-357.

Toxqui Furlong, M. G. 2013: Agua para todos en Puebla. Privatización y modernización del servicio, 1855-1883. Puebla, Benemérita Universidad Autónoma de Puebla. 